\title{
Periportal fibrosis, liver and spleen sizes among $S$. mansoni mono or co-infected individuals with human immunodeficiency virus-1 in fishing villages along Lake Victoria shores, North-Western, Tanzania
}

Humphrey D Mazigo ${ }^{1,2,4^{*}}$, David W Dunne ${ }^{4}$, Domenica Morona', Therese E Lutufyo', Safari M Kinung'hi', Geofrey Kaatano ${ }^{3}$ and Fred Nuwaha ${ }^{2}$

\begin{abstract}
Background: The pathogenesis of S. mansoni infection involves chronic inflammatory responses to parasite eggs which can be associated with a characteristic periportal fibrosis (PPF) and the progression to severe hepatosplenic disease. The effects of HIV-1 co-infection and the influence of $\mathrm{CD}^{+}$cell numbers on these clinical manifestations of chronic S. mansoni are not known. To understand the effects of HIV-1 co-infection on these morbidities, we examined S. mansoni ultrasound-detectable morbidities in relation to HIV-1 infection and $\mathrm{CD}^{+}{ }^{+}$cell counts, and other factors in fishing communities where the two infections are present.

Methods: Ultrasonographical examination was conducted during a cross-sectional study of 1,671 (aged 21-55 years) individuals in North-Western Tanzania. Blood samples were obtained for HIV-1 screening and CD4 ${ }^{+}$cell quantification. A single stool sample was examined for S. mansoni eggs using the Kato-Katz technique. A questionnaire was used to collect socio-demographic-economic information.

Results: The prevalence of PPF (grade C-F) was $13.79 \%$ and $15.01 \%$ for the HIV-1 infected and non-infected individuals $(P=0.72)$. Male gender $(P<0.001)$, age group $21-30$ years $(P<0.028)$ and, residential time of $11-20(P<0.01)$ and $\geq 21$ years $(P<0.01)$ were associated with PPF in S. mansoni infected individuals. The height-adjusted measurements of the left liver lobe were significantly larger in HIV-1/S. mansoni co-infected compared to S. mansoni only-infected individuals ( $\mathrm{t}=-2.0702$, $P<0.039$ ). Predictors of the height-adjusted measurements of the left liver lobe and spleen were age, male gender, malaria infection, fishing occupation, village of residence and heavy intensity of S. mansoni infection. After accounting for these factors, neither HIV-1 infection nor $\mathrm{CD}^{+}$cell counts predicted PPF, hepatosplenomegaly, measurements of the liver or spleen. Height-adjusted ultrasound measurements of the left liver lobe did not correlate with the CD4 ${ }^{+}$cells counts in co-infected individuals $(r=-0.16, P=0.084)$.

(Continued on next page)
\end{abstract}

\footnotetext{
* Correspondence: humphreymazigo@gmail.com

${ }^{1}$ Department of Medical Parasitology and Entomology, School of Medicine,

Catholic University of Health and Allied Sciences, P.O. Box 1464, Mwanza,

Tanzania

${ }^{2}$ Department of Disease Control and Environmental Health, School of Public

Health, College of Health Sciences, Makerere University, P.O. Box 7072,

Kampala, Uganda

Full list of author information is available at the end of the article
} 
(Continued from previous page)

Conclusion: S. mansoni-related PPF, liver and spleen enlargement are prevalent in the study population. The intensity of S. mansoni infection was associated with the enlargement of liver, spleen and hepatosplenomegaly. The PPF grades observed were similar in both HIV-1/S. mansoni co-infected and in those only infected with S. mansoni. There was no evidence that HIV-1 infection or CD4 ${ }^{+}$cells counts were associated with these S. mansoni morbidities.

Keywords: S. mansoni, HIV-1, Co-infection, Periportal fibrosis, Liver and spleen sizes, Tanzania

\section{Background}

Chronic S. mansoni infection can result in severe complications and life-threatening hepatosplenic disease $[1,2]$. The pathogenesis of the hepatosplenic form of the disease is a result of the chronic immunological responses mediated by $\mathrm{CD}^{+}$T-lymphocytes directed against S. mansoni eggs which are trapped within the host body tissues including the liver [2,3]. Immunological responses against the eggs of the parasite trapped in the liver are responsible for the development of periova granulomas, chronic exposure to which can be associated with the development of fibrosis of the liver portal tracts and associated morbidities [4,5]. Experimental murine model studies suggest that granuloma formation in S. mansoni infection is a CD4 ${ }^{+}$T-cells dependent process $[3,5-7]$. The $\mathrm{CD} 4^{+}$cells are predominantly associated with the secretion of $\mathrm{Th}_{2}$ cytokines which contributes to the development of hepatic fibrosis $[8,9]$. Evidence from immunodeficient mice (nude, T-cell depleted and severe combined immunodeficiency (SCID) mice characterized by the absence of $\mathrm{CD} 4^{+} \mathrm{T}$-lymphocytes and egg antibodies response) [10-13], indicate that these animals suffer exacerbated severe hepatic parenchyma damage with reduced granulomatous responses [10-13]. However, there are differences between liver morbidity in $S$. mansoni infected humans and mice; for example, infected mice do not develop the PPF seen in human infections $[8,14]$.

In human hosts, hepatosplenic disease is often accompanied by hepatic and splenic enlargement; progressive periportal fibrosis (PPF) can lead to portal hypertension and its sequelae $[1-3,6,8,9]$, including ascites, liver surface irregularities and portal-systemic venous shunts, with the risk of oesophageal varices and haematemesis [1-3,8,9]. Many of these manifestations of chronic morbidity can be detected and measured by ultrasonography and the degree of PPF severity is classified using a recommended World Health Organization grading scale, agreed under the Niamey protocol [15-17]. Although immunological responses play a crucial role in the development of hepatosplenic disease, epidemiological [18] and demographic factors are also very important, including the duration of residence in schistosomiasis endemic areas $[16,19,20]$, socio-economic factors such as the involvement in fishing activities [16], as well as environmental [18], genetical [21], parasitological factors [18,20-22] and co-infection with other tropical diseases such as malaria $[23,24]$. Hepatomegaly or splenomegaly associated with malaria infection is mainly a result of repeated inflammatory responses characterized by hyperplasia of reticuloendothelial and lymphoid tissues [25], which can be exacerbated by chronic S. mansoni infection [23-25]. Any study of the relationship between S. mansoni infection, HIV-1 infection, hepatosplenic disease and its squelae, has to take account of the effects of such factors.

The overall pathogenesis of HIV-1 infection is triggered by the destruction or depletion of $\mathrm{CD}^{+} \mathrm{T}$-lymphocytes which consequently lead to the loss of immune competence $[26,27]$ and an increase in the susceptibility of the infected individuals to other infectious diseases [26]. It has been hypothesized that the destructions of $\mathrm{CD}^{+}{ }^{+} \mathrm{T}$ lymphocytes by HIV-1 infection may alter the sizes of the left liver lobe and the patterns of hepatic fibrosis. This, in turn, may increase the risk of hepatic parenchymal damage due to an insufficient production of the $T h_{2}$ cytokines which are responsible for fibrogenesis [28,29]. In-vitro studies have shown that T-cells from individuals coinfected with HIV-1 and S. mansoni produced lower IL-4 and IL-10 and IFN- $\gamma$ [28]. The inability to stimulate these cells may lead to the development of a severe hepatic morbidity. Furthermore, the observation that $\mathrm{CD} 4^{+} \mathrm{T}$-cells are required for $S$. mansoni eggs excretion in mice [30,31] and that HIV-1 positive Kenyans infected with S. mansoni have impaired parasite eggs excretion that correlates with decreased $\mathrm{CD}^{+}$cell counts [32], suggest that the effects of HIV-1 on CD4 $4^{+}$cells counts could lead to more parasites eggs being retained in the host body organs. Thus, individuals co-infected with HIV-1 and S. mansoni may have altered ultrasonography detectable morbidities such as severe hepatomegaly and splenomegaly compared to those infected with $S$. mansoni alone. However, to date, limited evidence is available [33].

To investigate the hypothesis that individuals coinfected with HIV-1 and S. mansoni suffer severe ultrasound detectable morbidities as compared to individuals infected with only S. mansoni infection. The present study examined the prevalence and intensities of S. mansoni infection and the related morbidities using ultrasonography in HIV-1 infected and un-infected population (aged 21-55 years) to define the type of morbidities and 
evaluate the role of various known demographic and parasitological factors in development of these S. mansoni morbidities and their association with left liver lobe and spleen sizes, and hepatosplenomegaly. In addition, we tested if the ultrasound measurements of the left liver lobe are associated with the level of $\mathrm{CD}^{+}$cell counts in individuals co-infected with HIV-1 and S. mansoni infections.

\section{Methods}

\section{Study area, population and design}

The study area, inclusion and exclusion criteria and sampling procedures of the study participants are described in Mazigo et al. [34,35]. In brief, the study included four villages of North-Western Tanzania, bordering the southern shores of the Lake Victoria. All people who had lived in the study villages for more than two years (referred to as permanent residents) and aged 21 to 55 years were eligible for enrolment. Individuals with a history of treatment for schistosomiasis (praziquantel) in the past six months and those who were on antiretroviral treatment (ART) were excluded from the study at the baseline. A two-step sampling procedure was used to select households and household members to participate in the study [34,35].

\section{Data collection}

\section{(i) Demographic information}

Demographic information on sex, age, occupation, marital status, village of residence, number of years lived in current residence and level of education were collected with the use of a questionnaire [34]. The detailed demographic characteristics of the study participants are described in Mazigo et al. [34]. In brief, complete parasitological data and ultrasonographical data were obtained from 1,785 individuals aged $21-55$ years, excluding $n=114$ individuals who were positive in an hepatitis $\mathrm{C}$ serological assay. Therefore, a total of 1,671 individuals' data were available for the present analysis.

\section{(ii) Human Immunodeficiency Virus screening and CD4 ${ }^{+}$ analysis}

Human Immunodeficiency Virus-1 testing was conducted according to the Tanzanian National HIV algorithms which recommend the use of a rapid test qualitative immunoassay [36]; other procedures are described in detail in Mazigo et al. [34,35]. The quantification of $\mathrm{CD}^{+}$ cells was done using a FACSCalibur machine (Becton Dickinson-BD Biosciences, San Jose, CA, USA) following standard procedures [37]. Baseline results on HIV-1 infection are described in detail in Mazigo et al. [34,35]. Briefly, the prevalence of HIV-1 was $6.29 \%$, (95\% CI; 3.59-11.04).

\section{(iii) Parasitological screening for Schistosoma mansoni}

A single stool sample was collected from all study participants. Four Kato Katz thick smears were prepared from different parts of the single stool sample using a template of $41.7 \mathrm{mg}$ (Vestergaard Frandsen, Lausanne, Switzerland), following a standard protocol [38-40]. After 24 hours, the smears were independently examined for $S$. mansoni eggs by two experienced laboratory technicians of the National Institute for Medical Research (NIMR) laboratory. For quality assurance, a random sample of $10 \%$ of the negative and positive Kato Katz thick smears were re-examined by a third technician. At baseline, the overall prevalence of S. mansoni, HIV-1 infections and their relationship with demographic characteristics of the study participants are described in details in Mazigo et al. [34]. Briefly, the overall prevalence of $S$. mansoni was $47.85 \%$, (95\% CI; 40.46-56.57). Only 40\% ( $n=50)$ of the HIV-1 infected individuals were co-infected with S. mansoni [34].

\section{(iv) Parasitological screening for malaria}

A finger prick blood sample was used to prepare thick and thin blood films for malaria parasites diagnosis and stained in $10 \%$ Giemsa (Sigma). The slides were examined under a microscope using objective X 100 under oil-immersion [39]. Plasmodium falciparum parasite density was determined, as described elsewhere [39]. At baseline screening, the overall prevalence of malaria infection was $8.02 \%(134 / 1,671)$ and the overall geometrical mean parasite density was 450.41 parasites $/ \mu \mathrm{L}$. The prevalence of malaria did not vary by sex $\left(\chi^{2}=0.0425\right.$, $P=0.84)$ and age of the study participants $\left(X^{2}=5.7853\right.$, $P=0.12)$, though the age group 21-30 years $(11.39 \%)$ had a higher prevalence compared to other age groups. In terms of occupation, those involved in farming had a higher prevalence $(10.8 \%)$, than those involved in other economic activities but the difference was not significant $(P=0.09)$.

\section{(iv) Anthropometric measurements}

Body height was measured by means of a locally constructed stadiometer using a tape measure fixed on a wooden board, whereas body weight was measured using electronic bathroom scales.

\section{(v) Clinical and ultrasound examination}

All study participants were clinically examined for consistency of liver and spleen after submitting a single stool sample. The procedures used for examination are described in detail by Vennervald et al. [41]. An ultrasonographical examination of the study participant was carried out by two experienced radiographer using a portable ultrasound machine (Aloka, Tokyo). The modified Niamey Protocol was applied for classification of the 
level of pathology [15]. Both the examiner and the assistant were blinded with respect to the HIV-1 serostatus and S. mansoni results. The liver texture patterns, peripheral portal branches (PPBs), periportal fibrosis (PPF), thickness of PPB walls, spleen size, splenic vein (SV) diameter and ascites were assessed. Periportal fibrosis (PPF) was defined according to WHO [15] and the degree of PPF was categorized as A, B, C, D, E and F [15]. Periportal fibrosis grade $\mathrm{A}$ and $\mathrm{B}$ were classified as normal.

The liver length was measured along the para-sternal line (PLL), whereas the spleen length was measured along the mid clavicular line (MCL). The measurement of portal vein diameter (PVD) was done at a midway between its entrance of the portal hepatica and its bifurcation inside the liver [15].

\section{Treatment}

All individuals found infected with $S$. mansoni at baseline (aged 21-55 years), irrespective of their HIV-1 sero-status or $\mathrm{CD} 4^{+}$cell count levels, were treated with a single dose of praziquantel $(40 \mathrm{mg} / \mathrm{kg})$. Treatment was performed under direct observation (DOT) of a qualified nurse. Study participants received a cup of tea and some bread before treatment to relieve the mild side effects of praziquantel. In addition, after treatment, participants were requested to remain at the treatment point for two hours to observe and manage any possible adverse effects.

\section{Ethical considerations}

Ethical approval was obtained from the Higher Degrees Research and Ethics Committee of the School of Public Health, Makerere University (Institutional Review Board (IRB) -00005856/2011) and from the Bugando University College of Health Sciences and Allied Sciences-Institutional Review Board, (BREC/001/32/2011). Ethical clearance was granted by the National Ethical Review Committee, National Institute for Medical Research, Tanzania and the study was registered in the clinical trial network, Clinical Trial (Number:- NCT-01541631). The study received authorization from the regional and district administrative authorities of Mwanza region and Ilemela district. Swahili translated informed assent and consent forms were used to obtain children (15- $<18$ years) and adult participants' consent respectively. For illiterate individuals, a thumb print was used to sign the assent and consent forms after a clear description of the study objective. All HIV-1 infected individuals found to have $\mathrm{CD} 4^{+}<350$ cells $/ \mu \mathrm{L}$ were referred to the Care and Treatment Clinic (CTC) for assessment of their eligibility for antiretroviral therapy (ART).

\section{Data management and analysis}

The data were double entered using CSPro and the final data set was stored in a MYSQL database at the National Institute of Medical Research (NIMR) Mwanza centre.
Data were checked for consistency and errors were cleaned. Data analysis was performed using stata version 12 (Stata Corp, College station, Texas, USA). The ultrasound measurements of the liver, spleen and portal vein diameter of the study participants were compared between those who did or did not have detectable $S$. mansoni infection using t-test. Similarly, the t-test was used to compare organs sizes between individuals who were mono-infected with $S$. mansoni and those who were coinfected with S. mansoni and HIV-1.

To define the cut-off point between normal and enlarged organs for ultrasound measurements, such as enlarged spleen, enlargement of the left liver lobe and portal vein dilatation, the Niamey protocol was used [15].

To assess the contributions of intensities of S. mansoni and HIV-1 infections on the extent of the liver and spleen enlargement, linear regression models were constructed for height-adjusted measurements of the left liver lobe and the spleen. Explanatory variables included in the models were sex, age, occupation, village of residences, malaria infection, HIV-1 serostatus and intensities of S. mansoni. Bivariate and multivariable logistic regression models were also constructed to identify factors associated with PPF and hepatosplenomegaly. At bivariate analysis, individuals factors were analyzed with the outcome of interest and explanatory variable with $P$ value $<0.2$ were considered for multivariable analysis. Explanatory variables entered were the same for linear regression. Unadjusted and adjusted Odd Ratio and their 95\% confidence interval (95\% CI) were generated and used to measure the strength of association between outcome and explanatory variables. The Spearman correlation test was used to test any correlation between height adjusted left liver lobe ultrasound measurements and $\mathrm{CD} 4^{+}$counts in individuals co-infected with HIV-1 and $S$. mansoni. Values for $P<0.05$ were considered significant.

\section{Results}

\section{(a) Prevalence of periportal fibrosis (PPF) and associated}

\section{factors}

The overall prevalence PPF (grades C-F) was 14.78\% (247/1,671, 95\% CI: 13.28-16.72). In relation to S. mansoni infection, of the individuals detected with PPF, $52.23 \%(129 / 247)$ had detectable S. mansoni eggs in their stool samples and $47.77 \%(118 / 247)$ had no detectable $S$. mansoni eggs. In general, the prevalence of PPF did not vary by $S$. mansoni infection status $\left(\chi^{2}=2.6768, P=0.10\right)$ and categories of intensities of infection in terms of egg count (epg) $\left(x^{2}=6.1379, P=0.11\right)$. The stratification of PPF grades and infection with $S$. mansoni are shown Table 1 and there was no significance difference between individuals who were either infected or not with $S$. mansoni infection $(P=0.39)$. Of the 247 individuals with PPF, 
Table 1 Prevalence of peri-portal grades and hepatosplenomegaly in relation to Schistosoma mansoni infection status

\begin{tabular}{|c|c|c|c|c|}
\hline \multirow[t]{2}{*}{ Variables } & \multicolumn{2}{|c|}{ Schistosoma mansoni status } & \multirow[t]{2}{*}{$\div^{2}$} & \multirow[t]{2}{*}{$P$-values } \\
\hline & Negative $(\mathrm{N}=831)$ & Positive $(\mathrm{N}=840)$ & & \\
\hline \multicolumn{5}{|l|}{ Hepatosplenomegaly } \\
\hline \multirow[t]{2}{*}{ Both liver + spleen not enlarged } & 305 & 291 & 4.5425 & 0.21 \\
\hline & $(36.70)$ & $(34.64)$ & & \\
\hline \multirow[t]{2}{*}{ Only spleen enlarged } & 78 & 91 & & \\
\hline & $(9.39)$ & $(10.83)$ & & \\
\hline \multirow[t]{2}{*}{ Only liver enlarged } & 327 & 313 & & \\
\hline & (39.35) & $(37.26)$ & & \\
\hline \multirow[t]{2}{*}{ Both spleen and liver enlarged } & 121 & 145 & & \\
\hline & $(14.56)$ & $(17.26)$ & & \\
\hline \multicolumn{5}{|l|}{ Peri portal fibrosis grades } \\
\hline \multirow[t]{2}{*}{ Normal } & 713 & 710 & 4.1566 & 0.39 \\
\hline & $(85.80)$ & $(84.52)$ & & \\
\hline \multirow[t]{2}{*}{ Grade C } & 32 & 41 & & \\
\hline & (3.85) & $(4.88)$ & & \\
\hline \multirow[t]{2}{*}{ Grade D } & 66 & 64 & & \\
\hline & (7.94) & (7.62) & & \\
\hline \multirow[t]{2}{*}{ Grade E } & 15 & 20 & & \\
\hline & $(1.81)$ & $(2.38)$ & & \\
\hline \multirow[t]{2}{*}{ Grade F } & 5 & 4 & & \\
\hline & $(0.60)$ & $(0.48)$ & & \\
\hline
\end{tabular}

$29.55 \%(73 / 247)$ were grade C, $52.63 \%(130 / 247) \mathrm{D}$, $14.17 \%(35 / 247) \mathrm{E}$ and $3.64 \%(9 / 247)$ were grade F. Of the individuals infected with $S$. mansoni and having PPF, 31.78\% $(n=41 / 129)$ in grade C, 49.61\% $(n=63 /$ $129)$ in grade $D, 12.02 \%(n=20 / 129)$ in grade $E$ and $3.10 \%(n=4 / 129)$ in grade $F$ had egg positives Kato Katz slides.

In relation to other demographic factors, males individuals had a higher prevalence of PPF than females (157/247, 20.08\% versus 90/247, 10.31\%, $\chi^{2}=30.9943$, $P<0.001)$ and a higher prevalence of more severe fibrosis (grade D, E, or F) $(P<0.001)$. PPF prevalence did not significantly vary by age group $\left(X^{2}=1.3521, P=0.72\right)$, although the age group 31-40 years (15.08\%) and $41-50$ years $(16.94 \%)$ groups had the highest PPF prevalence. Individuals involved in fishing activities had the highest prevalence of PPF $\left(25.30 \%, X^{2}=26.0954, P<0.001\right)$. The prevalence of PPF varied significantly by villages of residence with Kayenze (17.02\%) and Igalagala (19.65\%) having the highest prevalence $\left(X^{2}=16.5998, P<0.001\right)$ and duration of residence $\left(\chi^{2}=14.2821, P=0.01\right)$, with those reported living in the study for 11-20 years (19.32\%) and $\geq 21$ years $(18.16 \%)$ having the highest prevalence.

In relation to HIV-1 infection, $13.79 \%$ and $15.01 \%$ of the HIV-1 infected and uninfected individuals had PPF $\left(\chi^{2}=0.1258, P=0.72\right)$ respectively. Of these $n=4$ had grade $C, n=8$ had grade $D$ and $n=4$ had grade $E-F$. The prevalence of PPF did not differ by HIV-1 serostatus, $\left(X^{2}=0.1258, P=0.72\right)$.

To ascertain the importance of HIV-1 infection as predictor of PPF, a logistic regression model that included $S$. mansoni infection or number of $S$. mansoni eggs per gram of faeces, duration of residency, age, village of residence, occupation, malaria infection and sex as explanatory factors was developed among $S$. mansoni infected individuals with PPF as the outcome variable (Table 2). A bivariate analysis, male gender $(P<0.004)$ and residential year of $11-$ 20 years $(P<0.035)$ were associated with PPF. At multivariable analysis, male gender $(\mathrm{AOR}=2.27,95 \% \mathrm{CI} ; 1.41-$ $3.65, P<0.001)$, age group $21-30$ years $(\mathrm{AOR}=2.45,95 \%$ CI: $1.09-5.47, P<0.028)$ and residential time, $11-20$ years $(\mathrm{AOR}=3.52,95 \% \mathrm{CI} ; 1.38-8.93, \quad P<0.01)$ and $\geq 21$ years $(\mathrm{AOR}=2.66,95 \% \mathrm{CI}: 1.27-5.58, P<0.01)($ Table 2$)$.

(b) Comparison of the height adjusted mean deviations of organs in relation to infection with $S$. mansoni

Table 3 shows the comparison of mean deviations of organs in relation to $S$. mansoni infection. In general, the height-adjusted ultrasound measurements of the left liver lobe $(\mathrm{t}=0.8851, P=0.38)$, spleen $(\mathrm{t}=-0.5639, P=0.57)$ and portal vein diameter $(\mathrm{t}=-0.1710, P=0.86)$ did not 
Table 2 Factors associated with Periportal fibrosis among resident of fishing villages of North-western Tanzania

\begin{tabular}{|c|c|c|c|c|c|c|}
\hline Variable & cOR & $95 \% \mathrm{Cl}$ & $P$-value & aOR & $95 \% \mathrm{Cl}$ & $P$-value \\
\hline \multicolumn{7}{|l|}{ Sex } \\
\hline Female & 1 & & & 1 & & \\
\hline Male & 1.79 & $1.21-2.68$ & 0.004 & 2.27 & $1.41-3.65$ & $0.001^{* *}$ \\
\hline \multicolumn{7}{|c|}{ Age (in years) } \\
\hline $21-30$ & 1.35 & $0.71-2.53$ & 0.36 & 2.45 & $1.09-5.47$ & $0.028^{* *}$ \\
\hline $31-40$ & 1.32 & $0.68-2.54$ & 0.40 & 1.42 & $0.62-3.26$ & 0.40 \\
\hline $41-50$ & 1.16 & $0.53-2.55$ & 0.71 & 1.34 & $0.56-3.28$ & 0.51 \\
\hline $51-55$ & 1 & & & 1 & & \\
\hline \multicolumn{7}{|l|}{ Occupation } \\
\hline$S S B^{*}$ & 1 & & & 1 & & \\
\hline Farming & 0.74 & $0.41-1.34$ & 0.33 & -— & -——- & -—— \\
\hline Fishing & 1.26 & $0.64-2.45$ & 0.50 & -— & -—- & 一一 \\
\hline \multicolumn{7}{|c|}{ Village of residence } \\
\hline Igombe & 1 & & & 1 & & \\
\hline Sangabuye & 0.52 & $0.26-1.03$ & 0.06 & 0.39 & $0.18-0.85$ & 0.018 \\
\hline Kayenze & 1.17 & $0.71-1.94$ & 0.53 & 1.05 & $0.59-1.85$ & 0.19 \\
\hline Igalagala & 1.44 & $0.79-2.62$ & 0.23 & 1.74 & $0.74-4.06$ & 0.19 \\
\hline \multicolumn{7}{|c|}{ Residential years } \\
\hline$\geq 2-5$ & 1 & & & 1 & & \\
\hline $6-10$ & 1.18 & $0.57-2.44$ & 0.64 & 1.09 & $0.49-2.45$ & 0.81 \\
\hline $11-20$ & 2.02 & $1.05-3.87$ & 0.035 & 3.52 & $1.38-8.93$ & $0.01^{* *}$ \\
\hline$\geq 21$ & 1.42 & $0.79-2.57$ & 0.24 & 2.66 & $1.27-5.58$ & $0.01^{* *}$ \\
\hline \multicolumn{7}{|c|}{ Malaria infection } \\
\hline No & 1 & & & 1 & & \\
\hline Yes & 0.57 & $0.26-1.24$ & 0.16 & 0.72 & $0.32-1.61$ & 0.43 \\
\hline \multicolumn{7}{|c|}{ HIV-1 infection } \\
\hline No & 1 & & & & & \\
\hline Yes & 0.90 & $0.39-2.08$ & 0.81 & -—- & -—- & -—- \\
\hline \multicolumn{7}{|c|}{ Intensity of S. mansoni ïnfection (epg) } \\
\hline $1-100$ & 1 & & & 1 & & \\
\hline $101-399$ & 0.91 & $0.55-1.49$ & 0.72 & 0.84 & $0.47-1.46$ & 0.53 \\
\hline$\geq 400$ & 1.38 & $0.89-2.13$ & 0.14 & 1.11 & $0.66-1.86$ & 0.68 \\
\hline
\end{tabular}

$\mathrm{SSB}^{*}=$ small scale business, $\mathrm{cOR}=$ Crude Odd Ratio, aOR $=$ Adjusted Odd Ratio.

** significant $P$-values for factors associated with peri-portal fibrosis.

differ significantly among individuals either infected or not with $S$. mansoni infection.

(c) Comparison of the height-adjusted size of the of the organs in relation to HIV-1 infection

Table 4 shows a comparison of the height-adjusted size of the left liver lobe, spleen and portal vein diameter in relation to HIV-1 infection. The height-adjusted ultrasound measurements of the left liver lobe were significantly larger in individuals co-infected with HIV-1 and S. mansoni compared to $S$. mansoni only infected individuals $(\mathrm{t}=-2.0702$, $P<0.039)$. However, the height-adjusted ultrasound measurements of the spleen $(t=-1.3664, P=0.17)$ and portal vein diameter $(t=0.8072, P=0.42)$ did not differ significantly between individuals co-infected with HIV-1 and $S$. mansoni infection compared to $S$. mansoni-only infected individuals.

(d) Correlation between the height-adjusted ultrasound measurements of the left liver lobe, spleen, portal vein diameter and intensity of S. mansoni infection

The Spearman correlation test was used to determine whether the size of the left liver lobe and spleen correlated with the intensity of S. mansoni infection. For 
Table 3 Comparison of the height adjusted mean deviations of organs stratified by infection with S. mansoni

\begin{tabular}{|c|c|c|c|c|}
\hline \multirow[t]{2}{*}{ Organomegaly } & \multicolumn{2}{|l|}{ Schistosoma mansoni status } & \multirow[t]{2}{*}{ F-ratio } & \multirow[t]{2}{*}{$P$-values } \\
\hline & $\begin{array}{l}\text { Not Infected with S. mansoni }(\mathrm{N}=831) \\
\text { deviations from mean }(95 \% \mathrm{Cl})\end{array}$ & $\begin{array}{l}\text { Infected with } S \text {. mansoni }(\mathrm{N}=840) \\
\text { deviations from mean }(95 \% \mathrm{Cl})\end{array}$ & & \\
\hline \multicolumn{5}{|l|}{ Liver } \\
\hline Left liver lobe length & $2.34(2.22-2.47)$ & $2.27(2.14-2.39)$ & 0.8851 & 0.38 \\
\hline \multicolumn{5}{|l|}{ Spleen } \\
\hline Spleen length & $1.19(1.06-1.31)$ & $1.23(1.11-1.35)$ & -0.5639 & 0.57 \\
\hline \multicolumn{5}{|l|}{ Portal vein Diameter } \\
\hline Portal vein length & $1.03(0.96-1.10)$ & $1.04(0.97-1.11)$ & -0.1710 & 0.86 \\
\hline
\end{tabular}

individuals infected with S. mansoni, the intensity of infection remained significantly correlated with height-adjusted length of the left liver lobe $(r=0.073, P<0.0244)$ and heightadjusted length of the spleen $(r=0.089, P<0.006)$. However, the height-adjusted portal vein $(r=0.004, P=0.89)$ and portal branch wall thickness $(r=0.0656, P=0.73)$ measurements did not correlate with $S$. mansoni intensity of infection.

(e) Correlation between the height-adjusted ultrasound measurements of the left liver lobe and $\mathrm{CD}^{+}$cell counts For individuals who were co-infected with HIV-1 and $S$. mansoni, the height-adjusted ultrasound measurements of the left liver lobe did not correlate with $\mathrm{CD} 4^{+} \mathrm{T}$-cell counts among the co-infected individuals $(r=-0.16, P=0.084)$ Figure 1.

(f) Predictors of left liver lobe hepatomegaly, splenomegaly and hepatosplenomegaly

To assess the contribution of HIV-1, S. mansoni and other explanatory variables on the extent of left liver lobe and spleen, linear regression models were developed with height adjusted ultrasound measurements of the left liver lobe and spleen as continuous outcome variables for individuals who had detectable S. mansoni eggs in faecal samples. The ultrasound adjusted left liver lobe measurements were significantly associated with the age of the study participants $(P<0.038)$, malaria infection $(P<0.038)$ and intensities of $S$. mansoni infection $(P<0.01)$. HIV-1 infection was not a significant predictor of left liver lobe ultrasound measurements $(P=0.069)$ (Table 5).

Table 6 shows the predictors of height-adjusted ultrasound measurements of the spleen. Spleen measurements were significantly associated with sex of the participants (being male, $P<0.002)$, fishing occupation $(P<0.005)$, village of residence (living in Kayenze village, $P<0.039$ and Igalagala village, $P<0.005)$, being infected with malaria parasite $(P<0.018)$ and HIV-1 infection $(P<0.05)$.

The prevalence of organomegaly (hepatomegaly, splenomegaly and hepatosplenomegaly) in relation to HIV-1 and $S$. mansoni infections is shown in Table 1 . Overall, based on the Niamey protocol categories, $13.73 \%(167 / 1,216)$ had an enlarged spleen, $59.70 \%(726 / 1,216)$ had hepatomegaly and $26.56 \%(323 / 1.256)$ had hepatosplenomegaly. There was no significant difference in the prevalence of these morbidities in individuals who were only infected with S. mansoni and those who were co-infected with HIV-1/S. mansoni (Fisher exact, $P=0.40$ ). Similarly, no significant difference was observed in relation to these morbidities in individuals with detectable $S$. mansoni eggs and those with no detectable eggs in their stool samples $(P=0.07)$. To ascertain the importance of demographic factors, HIV-1, malaria infection and intensities of S. mansoni infections, on the risk of developing hepatosplenomegaly among individuals infected with $S$. mansoni, a logistic

Table 4 Comparison of the height-adjusted size of the left liver, spleen and portal vein diameter in relation to infection with HIV-1 serostatus

\begin{tabular}{lll}
\hline Organomegaly & $\begin{array}{l}\text { HIV-1 serostatus } \\
\text { HIV-1 negative infected with S. mansoni } \\
(\mathbf{N}=\mathbf{7 9 0}) \text { deviations from mean }(\mathbf{9 5 \%} \mathbf{C I})\end{array}$ & $\begin{array}{l}\text { HIV-1 positive co-infected with S. mansoni } \\
\mathbf{( N = 5 0 )} \text { deviations from mean }(\mathbf{9 5 \%} \mathbf{C I})\end{array}$ \\
\hline $\begin{array}{l}\text { Liver } \\
\text { Left liver lobe length }\end{array}$ & $2.23(2.11-2.36)$ & $2.79(2.23-3.37)$ \\
$\begin{array}{l}\text { Spleen } \\
\text { Spleen length }\end{array}$ & $1.21(1.08-1.34)$ & $1.57(1.14-2.00)$ \\
$\begin{array}{l}\text { Portal vein Diameter } \\
\text { Portal vein length }\end{array}$ & $1.04(0.97-1.12)$ & -2.0702 \\
\hline
\end{tabular}

** significant $P$-values. 


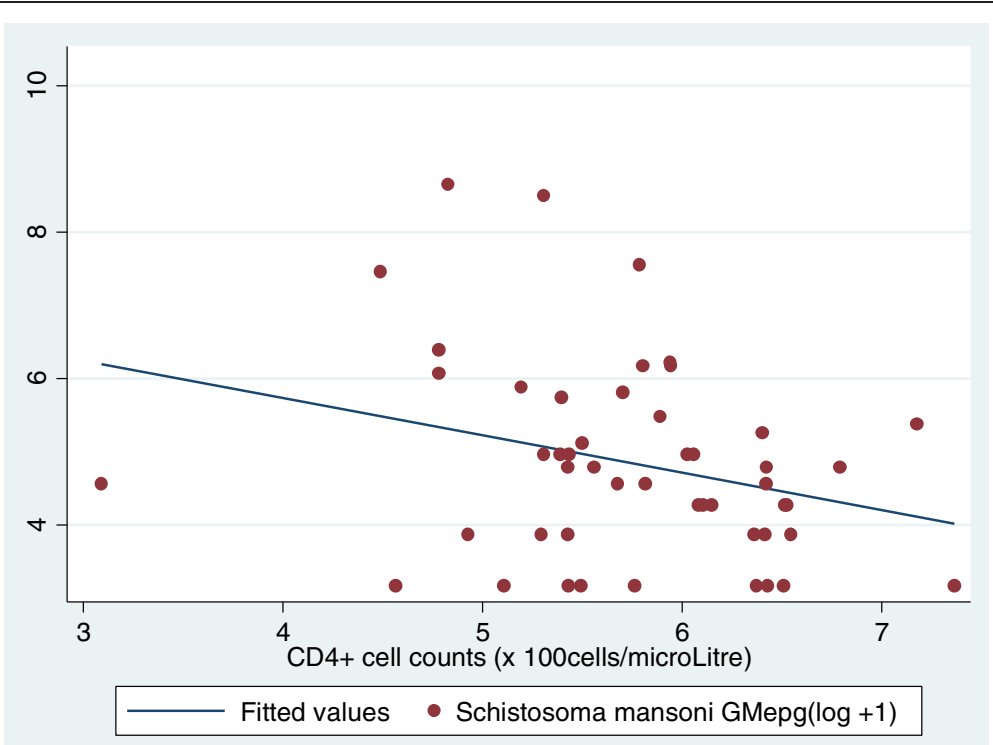

Figure 1 Scatter plot of correlation of left liver lobe ultrasound measurements and CD4 ${ }^{+}$counts in individuals co-infected with HIV-1 and S. mansoni. Ultrasound measurements were adjusted for height of individuals. The no correlation was observed between left liver lobe ultrasound measurements and $\mathrm{CD}^{+}$counts $(r=-0.16, P=0.084)$.

Table 5 Predictors of left liver lobe size among residents of fishing villages of North-Western Tanzania infected with S. mansoni

\begin{tabular}{lllll}
\hline Variable & $\hat{\mathbf{a}}$ & $\mathbf{S E}$ & $\mathbf{9 5 \%} \mathrm{Cl}$ & $\boldsymbol{P}$-values \\
\hline Sex & -0.1735 & 0.1390 & $-0.446-0.0994$ & 0.21 \\
Age & 0.0100 & 0.0048 & $0.00058-0.0195$ & $0.038^{* *}$
\end{tabular}

Occupation

$\mathrm{SSB}^{*}$

$\begin{array}{lllll}\text { Peasants } & 0.1357 & 0.2147 & -0.29-0.55 & 0.53 \\ \text { Fishing } & 0.1474 & 0.2649 & -0.37-0.67 & 0.58\end{array}$

Villages of residence

lgombe 1

$\begin{array}{lllll}\text { Sangabuye } & 0.2185 & 0.2025 & -0.17-0.62 & 0.28 \\ \text { Kayenze } & 0.1104 & 0.1762 & -0.24-0.46 & 0.53 \\ \text { Igalagala } & 0.3354 & 0.2873 & -0.23-0.89 & 0.24\end{array}$

Malaria infection

$\begin{array}{lllll}\text { No } & 1 & & & \\ \text { Yes } & 0.4142 & 0.1989 & 0.023-0.80 & 0.038^{* *}\end{array}$

\section{HIV-1 serostatus}

Negative $\quad 1$

Positive

0.5258

$0.2889-0.04-1.093$

0.069

\section{Schistosoma mansoni intensity (log epg)}

S. mansoni intensities $\quad 0.1076 \quad 0.0416 \quad 0.026-0.189 \quad 0.01^{* *}$ *SME - small scale business ** significant factors associated with left liver lobe hepatomegaly.

$\mathrm{R}^{2}=0.0264$, Adjusted $\mathrm{R}^{2}=0.0140 \mathrm{~F}=2.14$ and $P<0.02$.

Linear regression model was constructed for height adjusted ultrasound measurements of the left liver lobe(organ size as continuous variable- i.e. deviations from mean).
Table 6 Predictors of spleen size among residents of fishing villages of North-Western Tanzania infected with S. mansoni

\begin{tabular}{lllll}
\hline Variable & $\hat{\mathbf{a}}$ & $\mathbf{S E}$ & $\mathbf{9 5 \%} \mathrm{Cl}$ & $\boldsymbol{P}$-values \\
\hline Sex & 0.3968 & 0.1273 & $0.14-0.65$ & $0.002^{* *}$ \\
Age & -0.0005 & 0.0044 & $-0.009-0.0081$ & 0.91
\end{tabular}

Occupation

$\begin{array}{lllll}\text { SSB* }^{*} & 1 & & & \\ \text { Peasants } & 0.2445 & 0.1966 & -0.1413-0.63 & 0.21 \\ \text { Fishing } & 0.4726 & 0.2426 & -0.003-0.94 & 0.05^{* *}\end{array}$

Fishing $\quad 0.4726 \quad 0.2426-0.003-0.94 \quad 0.05^{* *}$

Villages of residence

lgombe

$\begin{array}{lllll}\text { Sangabuye } & 0.3164 & 0.1854 & -0.047-0.68 & 0.088 \\ \text { Kayenze } & 0.3333 & 0.1613 & 0.016-0.65 & 0.039^{* *} \\ \text { Igalagala } & 0.7331 & 0.2630 & 0.22-1.24 & 0.005^{* *}\end{array}$

Malaria infection

No 1

$\begin{array}{lllll}\text { Yes } & 0.43 & 0.1821 & 0.073-0.788 & 0.018^{* *}\end{array}$

HIV-1 serostatus

$\begin{array}{lllll}\text { Negative } & 1 & & & \\ \text { Positive } & 0.5186 & 0.2645 & -0.00076-1.037 & 0.05^{* *}\end{array}$

Schistosoma mansoni intensity (log epg)

$\begin{array}{lllll}\text { S. mansoni intensities } & 0.068 & 0.0381 & -0.0061-0.1435 & 0.072\end{array}$

*SSB - small scale business ** significant factors associated with splenomegaly. $\mathrm{R}^{2}=0.0564$, Adjusted $\mathrm{R}^{2}=0.0445 \mathrm{~F}=4.72$ and $P<0.0001$.

Linear regression model was constructed for height adjusted ultrasound measurements of the spleen (organ size as continuous variable-i.e. deviations from mean). 
regression model was constructed with hepatosplenomegaly as the outcome variable (Table 7). At bivariate analysis, variables significantly associated with hepatosplenomegaly were village of residence and heavy intensity of S. mansoni infection. At multivariable analysis, village of residence (living at Sangabuye village, $\mathrm{AOR}=2.21,95 \% \mathrm{CI} ; 1.15-4.25$, $P<0.017$, Kayenze village, $\mathrm{AOR}=2.06,95 \% \mathrm{CI} ; 1.15-3.71$, $P<0.016)$ and Igalagala, $\mathrm{AOR}=2.62,95 \% \mathrm{CI} ; 1.15-5.93$, $P<0.021)$ and being heavily infected with $S$. mansoni infection $(\mathrm{AOR}=1.54,95 \% \mathrm{CI} ; 1.01-2.39, P<0.047)$ remained independently associated with hepatosplenomegaly. HIV-1 infection was not a predictor (Table 7).

\section{Discussion}

In the present study population, we observed a considerably lower prevalence of PPF (grade C-F) than what previously reported in studies from the same geographical setting (16.7\%) and on the islands of Ukerewe (36\% and 41.5\%), North-Western Tanzania [42,43]. Similarly, in comparison to other studies that used the Niamey protocol in sub-Saharan Africa, our prevalence of PPF was low $[18,19,44]$. The observed variations in PPF between various epidemiological settings can partly be explained by differences in prevalence and intensities of $S$. mansoni infection, the focal nature of transmission of the disease $[18,19,45-48]$, the genetic background of the endemic communities and the length of time individuals have been exposed to $S$. mansoni infection [21,44]. In addition, co-infection with other tropical diseases such as malaria [46], differences in parasites strains [49] and immune responses [5] may contribute to the observed variation in prevalence of PPF between communities.

It has been hypothesized that HIV-1 infection, pathogenesis of which leads to a decreased level of $\mathrm{CD}^{+}$cell

Table 7 Predictors of hepatosplenomegaly among residents of fishing villages of North-Western Tanzania infected with S. mansoni infection

\begin{tabular}{|c|c|c|c|c|c|c|}
\hline Variable & COR & $95 \% \mathrm{Cl}$ & $P$-values & AOR & $95 \% \mathrm{Cl}$ & $P$-values \\
\hline \multicolumn{7}{|l|}{ Sex } \\
\hline Female & 1 & & & 1 & & \\
\hline Male & 1.24 & $0.89-1.71$ & 0.19 & 1.18 & $0.79-1.76$ & 0.42 \\
\hline \multicolumn{7}{|l|}{ Age (in years) } \\
\hline $21-30$ & 0.81 & $0.45-1.46$ & 0.48 & 0.65 & $0.34-1.22$ & 0.18 \\
\hline $31-40$ & 0.81 & $0.44-1.48$ & 0.49 & 0.59 & $0.31-1.13$ & 0.11 \\
\hline $41-50$ & 0.91 & $0.44-1.88$ & 0.79 & 0.66 & $0.30-1.45$ & 0.30 \\
\hline $51-60$ & 1 & & & 1 & & \\
\hline \multicolumn{7}{|l|}{ Occupation } \\
\hline $\mathrm{SSB}^{*}$ & 1 & & & 1 & & \\
\hline Peasants & 1.14 & $0.66-1.95$ & 0.64 & 0.78 & $0.42-1.45$ & 0.43 \\
\hline Fishing & 1.51 & $0.80-2.83$ & 0.20 & 1.12 & $0.53-2.35$ & 0.77 \\
\hline \multicolumn{7}{|c|}{ Village of residence } \\
\hline Igombe & 1 & & & 1 & & \\
\hline Sangabuye & 1.98 & $1.15-3.43$ & 0.014 & 2.21 & $1.15-4.25$ & $0.017^{* *}$ \\
\hline Kayenze & 1.84 & $1.11-3.03$ & 0.017 & 2.06 & $1.15-3.71$ & $0.016^{* *}$ \\
\hline Igalagala & 2.36 & $1.33-4.17$ & 0.003 & 2.62 & $1.15-5.93$ & $0.021^{* *}$ \\
\hline \multicolumn{7}{|c|}{ Malaria infection } \\
\hline No & 1 & & & 1 & & \\
\hline Yes & 1.31 & $0.78-2.16$ & 0.29 & 1.34 & $0.78-2.28$ & 0.29 \\
\hline \multicolumn{7}{|c|}{ HIV-1 serostatus } \\
\hline Negative & 1 & & & 1 & 1 & \\
\hline Positive & 1.60 & $0.83-3.09$ & 0.16 & 1.63 & $0.65-1.72$ & 0.82 \\
\hline \multicolumn{7}{|c|}{ Intensity of Schistosoma mansoni infection (epg) } \\
\hline $1-100$ epg & 1 & & & 1 & & \\
\hline $101-399$ epg & 1.15 & $0.75-1.76$ & 0.53 & 1.06 & $0.65-1.72$ & 0.82 \\
\hline$\geq 400$ epg & 1.59 & $1.09-2.32$ & 0.015 & 1.54 & $1.01-2.39$ & $0.047^{* *}$ \\
\hline
\end{tabular}


counts [50] may affect the development of hepatic morbidities in HIV-1/S. mansoni infected individuals. Thus, individuals co-infected with HIV-1/S. mansoni may present with severe PPF grades. We have observed HIV-1 positive individuals either with $S$. mansoni detectable egg in their stool samples or not presenting with PPF. There was no significant difference in prevalence of PPF between individuals co-infected with HIV/S. mansoni and those who were not infected with HIV-1 infection. Consistent findings were reported among Kenyan patients co-infected with HIV-1/S. mansoni [33]. HIV-1 infected individuals were not at a higher risk of either experiencing severe or different PPF grades associated with $S$. mansoni infection than HIV-1 non-infected individuals [33].

On the other hand, the explanatory factors observed to be associated with PPF in the present study have also been reported by similar studies in $S$. mansoni endemic areas $[18,19,21,43]$. The gender related association with PPF mainly reflect either gender-specific factors $[18,21]$ or differences in the length of exposure between sexes to risk areas [21]. The development of PPF and its associated morbidities detected by ultrasound, can take years of infection to become manifest. Increased duration of residence in high risk areas, which defines the length of exposure to potential risk areas characterized by an intense transmission and the interactions of immune system and S. mansoni eggs trapped in the host body, remains an important factor for the development of these morbidities $[5,8,19]$. Our present work and those of other authors $[19,21]$, we observed that the risk of periportal fibrosis was higher after an individual have been exposed for more than a decade.

HIV-1 infection or its immunodeficiency, as measured in term of $\mathrm{CD}^{+}$cell counts, was not associated with PPF. It is worth to note that the presence of relatively non-severely $\mathrm{CD} 4^{+}$depleted individuals observed in the present study could have contributed to the lack of association between PPF and HIV-1 or $\mathrm{CD}^{+}$count levels. However, in the absence of HIV-1 infection, decreased $\mathrm{CD} 4{ }^{+}$cell counts with increased PPF grades score have been observed, in individuals who had PPF grades D/E and had lower median $\mathrm{CD} 4^{+}$cell counts [33]. Retesting this hypothesis with a larger study population would be needed to allow a definitive conclusion.

In the present study, we also assessed if HIV-1 infection had an influence on the height adjusted size of the left liver lobe, spleen and portal vein diameter among individuals infected with $S$. mansoni. Our findings indicate that the height-adjusted size of the left liver lobe was significantly enlarged in individuals co-infected with HIV-1 and $S$. mansoni compared to individuals infected with $S$. mansoni only. The chronic immune activation associated with the pathogenesis of HIV-1 infection, which also targets other immune cells such as macrophages, does contribute to the increase in the size of the left liver lobe $[51,52]$. Also, evidence from immunological studies has shown that the left liver lobe predominantly increases in size in S. mansoni infection [5,9], and epidemiological studies have shown the relationship between the increase in size of the left liver lobe and the intensity of $S$. mansoni infection $[16,18,20,42,53,54]$. Perhaps, these observations suggest that, in co-infected individuals, HIV-1 and S. mansoni may have additive effects on the size of the left liver lobe, with S. mansoni infection influencing the size of the organ in intensity-dependent manner. This observation has also been reported in individuals co-infected with $P$. falciparum and S. mansoni, in which $P$. falciparum was associated with hepatosplenomegaly exacerbated by the intensity of $S$. mansoni infection in dependent manner [23,24]. The increase in size of the left liver lobe in HIV-1 infected individuals co-infected with other tropical diseases, pathogenesis of which involve the liver has been also reported for HIV-1/Hepatitis-C coinfection [55]. Our findings on the contribution of S. mansoni and HIV-1 infections on the size of the liver present an important clinical feature for evaluating and managing hepatomegaly in HIV-1 infected individuals living in $S$. mansoni endemic countries. S. mansoni should be considered as one of the differential diagnosis in causing hepatomegaly in HIV-1 infected individuals.

'In the present study population, no correlation was observed between the left liver lobe size and $\mathrm{CD}_{4}^{+} \mathrm{T}$ - cell counts among individuals co-infected with $S$. mansoni and HIV-1 infection. Evidence from S. mansoni animal model studies, S. mansoni infected immunodeficient mice have reduced ability to form protective granulomas and suffer severe hepatic parenchymal cell damage caused by hepatotoxins secreted from parasite eggs $[3,56]$. In Western Kenya, the level of glutamic oxaloacetic transminase (GOT) enzymes, markers of liver parenchyma damage, did not correlate significantly with $\mathrm{CD} 4^{+} \mathrm{T}$-cell counts [33], suggesting the reduced level $\mathrm{CD}^{+}$cells observed were still protective against $S$. mansoni egg hepatotoxins, perhaps by continuing to support the production of antiegg hepatotoxins. It is worth noting that immunosuppressed mice studies result a much greater depletion of $\mathrm{CD} 4^{+} \mathrm{T}$-cells than is seen in the individuals included in this or previous human studies.

On the other hand, S. mansoni egg counts correlated significantly with the height-adjusted ultrasound measurements of the left liver lobe and the spleen. In addition, linear regression analysis revealed a number of factors which were either associated height-adjusted ultrasound measurements of the left liver lobe or the spleen. These explanatory factors observed in the present study have also been described in previous studies to interact in causing $S$. mansoni-related left liver lobe hepatomegaly, splenomegaly and hepatosplenomegaly in different age groups 
$[18,20,21]$. The association between these factors with organomegaly reflects the variation in transmission intensity of $S$. mansoni between geographical areas, age and sex differences in the exposure to $S$. mansoni risk areas [53]. In high endemic $S$. mansoni transmission areas, children are often infected within the first two or three of life males are suffer high infection intensities than females and intensity of infection increases with age [5]. In these areas, the majority of adults with an increased risk of exposure to infection, such as fishermen, can have significantly enlarged left liver lobe, spleen or both. However, enlarged left liver lobe and spleen, can also found in some areas to be highly prevalent in younger age groups, [5,53]. In these younger groups, left liver lobe size has been shown to correlate with high intensities of S. mansoni infection [16,20,53,57]. Similarly, the contribution of $P$. falciparum infection to the left liver lobe and spleen enlargement, and hepatosplenomegaly has been repeatedly reported in endemic areas [23,24]. Where co-infection of S. mansoni and P. falciparum occurs, these infections have synergistic effects in causing the enlargement of the left liver lobe [23,24].

Our study was subject to some limitations. The small number of $S$. mansoni/HIV-1 co-infected individuals could have affected the power of the study to detect particular changes in those individuals. Thus, some caution must be taken when the interpretation of these findings is carried out. However, despite this limitation, this was a community-based study which recruited a large number of participants living in potential risk areas for $S$. mansoni and HIV-1 infections.

\section{Conclusion}

Schistosoma mansoni-related morbidities such as PPF, enlarged left liver lobe, enlarged spleen and hepatosplenomegaly are present in the study population and are associated with various risk factors, including the intensity of $S$. mansoni infection. HIV-1 infected individuals, either with detectable $S$. mansoni eggs in their stool samples or not, had PPF, enlarged left liver lobe, enlarged spleen and hepatosplenomegaly. The PPF grades observed in HIV-1/S. mansoni co-infected individuals were similar to those individuals infected only with $S$. mansoni. However, HIV-1 infection or $\mathrm{CD}^{+}{ }^{+}$cell counts were not associated with PPF grades.

Our results indicate that the sizes of the left liver lobe, spleen and portal vein diameter did not vary between individuals infected or not infected with $S$. mansoni infection, thus indicating that current S. mansoni infection was not the only underlying cause of enlarged liver and spleen in the present study population. Individuals coinfected with S. mansoni and HIV-1 infection had a significantly larger size of the left liver lobe as compared to individuals with S. mansoni-only infection, thus indicating that, the two infections could interact in causing the enlargement of the left liver lobe. However, on a regression model, HIV-1 infection was not a predictor of the enlargement of the left liver lobe and immunodeficiencies effects of HIV-1 infection, as measured by $\mathrm{CD}^{+}{ }^{+} \mathrm{T}$-cell levels in co-infected individuals, did not correlate positively with the height-adjusted ultrasound measurements of the left liver lobe. Lastly, the implication of our observations is that individuals co-infected with HIV-1/S. mansoni, although affected by a $S$. mansoni related organomegaly similar to $S$. mansoni only-infected individuals, could be suffering severe enlargement of these organs. To reduce the burden of other infections and their associated morbidities, they should be either routinely screened and treated when visiting care and treatment clinics (CTC) or other public health measures should be included in the CTC package to reduce their exposure to $S$. mansoni infection.

\section{Competing interests}

The authors declare that they have no competing interests.

\section{Authors' contributions}

HDM, DWD, SMK, FN designed the study. HDM and FN participated in data analysis. HDM drafted the first version of the manuscript. HDM, TEL and GK participated in data collection. All authors read and approved the final manuscript, contributed to the critical review and made substantial contributions to its content.

\section{Acknowledgements}

This work was supported by Training Health Researchers into Vocational Excellence in East Africa (THRiVE), grant number 087540 funded by the Wellcome Trust. Its contents are solely the responsibility of the authors and do not necessarily represent the official views of the supporting offices. DWD and HDM acknowledge additional funds from Cambridge-Africa Alborada Research fund. HDM acknowledge additional funding support from Dan Davis Prize Scholarship, Tel Aviv University, Israel and the Special Programme for Research and Training in Tropical Diseases, co-sponsored by UNICEF, UNDP, the World Bank and WHO". We acknowledge the technical and financial assistance from the National Institute for Medical Research (NIMR) Mwanza centre main laboratory staff and the management team and the Catholic University of Health and Allied Sciences and Bugando Medical Centre, Mwanza. We thank all the study participants and the local government for allowing us to carry out this study.

\section{Author details}

${ }^{1}$ Department of Medical Parasitology and Entomology, School of Medicine, Catholic University of Health and Allied Sciences, P.O. Box 1464, Mwanza, Tanzania. ${ }^{2}$ Department of Disease Control and Environmental Health, School of Public Health, College of Health Sciences, Makerere University, P.O. Box 7072, Kampala, Uganda. ${ }^{3}$ National Institute for Medical Research, Mwanza Research Centre, P.O. Box 1462, Mwanza, Tanzania. ${ }^{4}$ Department of Pathology, Division of Microbiology \& Parasitology, Cambridge University, Tennis Court Road, Cambridge CB2 1QP, UK.

Received: 20 March 2015 Accepted: 27 April 2015

Published online: 07 May 2015

\section{References}

1. King $\mathrm{CH}$, Dangerfield-Cha M. The unacknowledged impact of chronic schistosomiasis. Chronic Illin. 2008;4(1):65-79.

2. van der Werf MJ, De Vlas SJ, Brooker S, Looman CW, Nagelkerke NJ, Habbema JDF, et al. Quantification of clinical morbidity associated with schistosome infection in sub-Saharan Africa. Acta Trop. 2003;86(2):125-39.

3. Dunne DW, Pearce EJ. Immunology of hepatosplenic schistosomiasis mansoni: a human perspective. Micro Infect. 1999;1(7):553-60.

4. Cheever AW, Andrade ZA. Pathological lesions associated with Schistosoma mansoni infection in man. Trans R Soc Trop Med Hyg. 1967;61(5):626-39. 
5. Butterworth AE, Curry AJ, Dunne DW, Fulford AJ, Kimani G, Kariuki HC, et al. Immunity and morbidity in human schistosomiasis mansoni. Trop Geog Med. 1994:46(4):197-208.

6. Cheever AW. A quantitative post-mortem study of Schistosomiasis mansoni in man. Ame J Trop Med Hyg. 1968;17(1):38-64.

7. Warren KS. Hepatosplenic schistosomiasis mansoni: an immunologic disease. Bull New York Acad Med. 1975;51(4):545-50.

8. Cheever AW, Hoffmann KF, Wynn TA. Immunopathology of schistosomiasis mansoni in mice and men. Immunol Today. 2000;21(9):465-6.

9. Pearce EJ, MacDonald AS. The immunobiology of schistosomiasis. Nat Rev Immunol. 2002;2(7):499-511.

10. Byram JE, Von Lichtenberg F. Altered schistosome granuloma formation in nude mice. Am J Trop Med Hyg. 1977;26(5 Pt 1):944-56.

11. Byram JE, Doenhoff MJ, Musallam R, Brink LH, Von Lichtenberg F. Schistosoma mansoni infections in T-cell deprived mice, and the ameliorating effect of administering homologous chronic infection serum. II. Pathology. Am J Trop Med Hyg. 1979;28(2):274-85.

12. Doenhoff M, Musallam R, Bain J, McGregor A. Schistosoma mansoni infections in T-cell deprived mice, and the ameliorating effect of administering homologous chronic infection serum. I. Pathogenesis. Am J Trop Med Hyg. 1979;28(2):260-3.

13. Fallon PG, Dunne DW. Tolerization of mice to Schistosoma mansoni egg antigens causes elevated type 1 and diminished type 2 cytokine responses and increased mortality in acute infection. J Immunol. 1999;162(7):4122-32.

14. Fallon PG. Immunopathology of schistosomiasis: a cautionary tale of mice and men. Immunol Today. 2000;21(1):29-35.

15. Richter J, Hatz C, Campagne G, Bergquist N, Jenkins JM. Ultrasound in schistosomiasis: a practical guide to the standard use of ultrasonography for assessment of schistosomiasis-related morbidity: second international workshop, October 22-26 1996, Niamey, Niger. Geneva: Tropical Deases Researche, World Health Organization; 2000.

16. Kardorff R, Gabone RM, Mugashe C, Obiga D, Ramarokoto CE, Mahlert C, et al. Schistosoma mansoni-related morbidity on Ukerewe Island, Tanzania: clinical, ultrasonographical and biochemical parameters. Trop Med Intern Health. 1997;2(3):230-9.

17. Kardorff R, Stelma FF, Vocke AK, Yazdanpanah Y, Thomas AK, Mbaye A, et al. Ultrasonography in a Senegalese community recently exposed to Schistosoma mansoni infection. Am J Trop Med Hyg. 1996;54(6):586-90.

18. Boisier $P$, Ramarokoto CE, Ravoniarimbinina P, Rabarijaona L, Ravaoalimalala V. Geographic differences in hepatosplenic complications of schistosomiasis mansoni and explanatory factors of morbidity. Trop Med Intern Health. 2001;6(9):699-706

19. Booth M, Vennervald BJ, Kabatereine NB, Kazibwe F, Ouma JH, Kariuki CH, et al. Hepatosplenic morbidity in two neighbouring communities in Uganda with high levels of Schistosoma mansoni infection but very different durations of residence. Trans R Soc Trop Med Hyg. 2004;98(2):125-36.

20. Berhe N, Myrvang B, Gundersen SG. Intensity of Schistosoma mansoni, hepatitis B, age, and sex predict levels of hepatic periportal thickening/fibrosis (PPT/F): a large-scale community-based study in Ethiopia. Am J Trop Med Hyg. 2007;77(6):1079-86

21. Mohamed-Ali Q, Elwali NE, Abdelhameed AA, Mergani A, Rahoud S, Elagib $\mathrm{KE}$, et al. Susceptibility to periportal (Symmers) fibrosis in human schistosoma mansoni infections: evidence that intensity and duration of infection, gender, and inherited factors are critical in disease progression. J Infect Dis. 1999;180(4):1298-306

22. Smith $\mathrm{DH}$, Warren $\mathrm{KS}$, Mahmoud A. Morbidity in schistosomiasis mansoni in relation to intensity of infection: study of a community in Kisumu, Kenya. Am J Trop Med Hyg. 1979;28(2):220

23. Wilson S, Vennervald BJ, Kadzo H, Ireri E, Amaganga C, Booth M, et al. Hepatosplenomegaly in Kenyan schoolchildren: exacerbation by concurrent chronic exposure to malaria and Schistosoma mansoni infection. Trop Med Int Health. 2007;12(12):1442-9.

24. Wilson S, Jones FM, Mwatha JK, Kimani G, Booth M, Kariuki HC, et al. Hepatosplenomegaly associated with chronic malaria exposure: evidence for a pro-inflammatory mechanism exacerbated by schistosomiasis. Parasite Immunol. 2009;31(2):64-71.

25. Buffet PA, Safeukui I, Deplaine G, Brousse V, Prendki V, Thellier M, et al. The pathogenesis of Plasmodium falciparum malaria in humans: insights from splenic physiology. Blood. 2011;117(2):381-92.

26. Borkow G, Bentwich Z. Chronic immune activation associated with chronic helminthic and human immunodeficiency virus infections: role of hyporesponsiveness and anergy. Clinl Microb Rev. 2004;17(4):1012-30.
27. Stevenson M. HIV-1 pathogenesis. Nature Med. 2003;9(7):853-60

28. Mwinzi PN, Karanja DM, Colley DG, Orago AS, Secor WE. Cellular immune responses of schistosomiasis patients are altered by human immunodeficiency virus type 1 coinfection. J Infect Dis. 2001;184(4):488-96.

29. Maggi E, Mazzetti M, Ravina A, Annunziato F, De Carli M, Piccinni MP, et al. Ability of HIV to promote a $\mathrm{TH} 1$ to $\mathrm{TH} 0$ shift and to replicate preferentially in TH2 and THO cells. Science. 1994;265(5169):244-8.

30. Doenhoff MJ, Bain J. The immune-dependence of schistosomicidal chemotherapy: relative lack of efficacy of an antimonial in Schistosoma mansoni-infected mice deprived of their T-cells and the demonstration of drug-antiserum synergy. Clin Exp Immunol. 1978;33(2):232-8.

31. Doenhoff MJ, Pearson S, Dunne DW, Bickle Q, Lucas S, Bain J, et al. Immunological control of hepatotoxicity and parasite egg excretion in Schistosoma mansoni infections: stage specificity of the reactivity of immune serum in T-cell deprived mice. Trans R Soc Trop Med Hyg. 1981;75(1):41-53.

32. Karanja DM, Colley DG, Nahlen BL, Ouma JH, Secor WE. Studies on schistosomiasis in western Kenya: I. Evidence for immune-facilitated excretion of schistosome eggs from patients with Schistosoma mansoni and human immunodeficiency virus coinfections. Ame J Trop Med Hyg. 1997;56(5):515-21.

33. Mwinzi PN, Karanja DM, Kareko I, Magak PW, Orago AS, Colley DG, et al. Short report: evaluation of hepatic fibrosis in persons co-infected with Schistosoma mansoni and human immunodeficiency virus 1. Am J Trop Med Hyg. 2004;71(6):783-6.

34. Mazigo HD, Dunne DW, Wilson S, Kinung Hi SM, De Moira A, Jones FM, et al. Co-infection with Schistosoma mansoni and Human Immunodeficiency Virus-1 (HIV-1) among residents of fishing villages of north-western Tanzania. Parasit Vectors. 2014:7(1):587.

35. Mazigo HD, Dunne DW, Kinung'hi SM, Nuwaha F. Praziquantel efficacy against Schistosoma mansoni among HIV-1 infected and uninfected adults living in fishing villages along Lake Victoria, Northwest Tanzania. Infect Dis Pov. 2014;3:47.

36. Lyamuya EF, Aboud S, Urassa WK, Sufi J, Mbwana J, Ndugulile F, et al. Evaluation of simple rapid HIV assays and development of national rapid HIV test algorithms in Dar es Salaam, Tanzania. BMC Infect Dis. 2009;9:19.

37. Borato DCK, Carraro E, Ribas SRW, Kalva-Filho CA, Vellosa JCR, Rebuglio JC Comparison of two methodologies for CD4+ T lymphocytes relative counting on immune monitoring of patients with human immunodeficiency virus. The Sc World J. 2012

38. Katz N, Chaves A, Pellegrino J. A simple device for quantitative stool thick-smear technique in Schistosomiasis mansoni. Rev Inst MedTrop Sao Paulo. 1972;14(6):397-400

39. WHO. Basic laboratory methods in medical parasitology. 1991.

40. WHO. Prevention and control of schistosomiasis and soil-transmitted helminthiasis. World Health Organization technical report series. 2002, 912:i.

41. Vennervald BJ, Kenty L, Butterworth AE, Kariuki CH, Kadzo H, Ireri E, et al, Detailed clinical and ultrasound examination of children and adolescents in a Schistosoma mansoni endemic area in Kenya: hepatosplenic disease in the absence of portal fibrosis. Trop Med Intern Health. 2004;9(4):461-70.

42. Malenganisho WL, Magnussen P, Friis H, Siza J, Kaatano G, Temu M, et al. Schistosoma mansoni morbidity among adults in two villages along Lake Victoria shores in Mwanza District, Tanzania. Trans R Soc Trop Med Hyg. 2008;102(6):532-41.

43. El Scheich T, Hofer L, Kaatano G, Foya J, Odhiambo D, Igogote J, et al. Hepatosplenic morbidity due to Schistosoma mansoni in schoolchildren on Ukerewe Island, Tanzania. Parasitol Res. 2012;110;6:2015-20.

44. Blanton RE, Salam EA, Kariuki HC, Magak P, Silva LK, Muchiri EM, et al. Population-based differences in Schistosoma mansoni- and hepatitis C-induced disease. J Infect Dis. 2002;185(11):1644-9.

45. Handzel T, Karanja D, Addiss DG, Hightower AW, Rosen DH, Moyou-Somo R, et al. Geographic distribution of schistosomiasis and soil-transmitted helminths in Western Kenya: implications for anthelminthic mass treatment. Am J Trop Med Hyg. 2003;69(3):318-23.

46. Booth M, Vennervald BJ, Kenty L, Butterworth AE, Kariuki HC, Kadzo H, et al. Micro-geographical variation in exposure to Schistosoma mansoni and malaria, and exacerbation of splenomegaly in Kenyan school-aged children. BMC Infect Dis. 2004;4:13.

47. Meurs L, Mbow M, Boon N, van den Broeck F, Vereecken K, Dieye TN, et al. Micro-geographical heterogeneity in Schistosoma mansoni and S. haematobium infection and morbidity in a co-endemic community in northern Senegal. PLoS Negl Trop Dis. 2013;7(12):e2608. 
48. Guyatt H, Gryseels B, Smith T, Tanner M. Assessing the public health importance of Schistosoma mansoni in different endemic areas: attributable fraction estimates as an approach. Am J Trop Med Hyg. 1995;53(6):660-7.

49. Thiongo FW, Madsen $\mathrm{H}$, Ouma JH, Andreassen J, Christensen NO. Host-parasite relationships in infections with two Kenyan isolates of Schistosoma mansoni in NMRI mice. J Parasitol. 1997:83(2):330-2.

50. Secor WE, Sundstrom JB. Below the belt: new insights into potential complications of HIV-1/schistosome coinfections. Curr Opin Infect Dis. 2007;20(5):519-23.

51. Maartens G, Celum C, Lewin SR. HIV infection: epidemiology, pathogenesis, treatment, and prevention. Lancet. 2014;384(9939):258-71.

52. Weber J. The pathogenesis of HIV-1 infection. Brit Med Bull. 2001;58:61-72

53. Kabatereine N, Kemijumbi J, Ouma J, Kariuki H, Richter J, Kadzo H, et al. Epidemiology and morbidity of Schistosoma mansoni infection in a fishing community along Lake Albert in Uganda. Trans R Soc Trop Med Hyg. 2004;98(12):711-8

54. Lehman Jr JS, Mott KE, Morrow Jr RH, Muniz TM, Boyer MH. The intensity and effects of infection with Schistosoma mansoni in a rural community in northeast Brazil. Am J Trop Med Hyg. 1976;25(2):285-94.

55. Vezozzo DC, Mendes-Correa MC, Cunha-Silva M, Alvarado-Mora MV, Franca $J$, Sebba JL, et al. Strong correlation by ultrasonography of hepatomegaly and the presence of co-infection in HIV/HCV cirrhotic patients. Braz J Infect Dis. 2013:17(2):150-5.

56. Everts B, Perona-Wright $\mathrm{G}$, Smits $\mathrm{HH}$, Hokke $\mathrm{CH}$, van der Ham AJ, Fitzsimmons CM, et al. Omega-1, a glycoprotein secreted by Schistosoma mansoni eggs, drives Th2 responses. J Exp Med. 2009;206(8):1673-80.

57. Mackenjee MK, Coovadia HM, Chutte CH. Clinical recognition of mild hepatic schistosomiasis in an endemic area. Trans R Soc Trop Med Hyg. 1984;78(1):13-5

\section{Submit your next manuscript to BioMed Central and take full advantage of:}

- Convenient online submission

- Thorough peer review

- No space constraints or color figure charges

- Immediate publication on acceptance

- Inclusion in PubMed, CAS, Scopus and Google Scholar

- Research which is freely available for redistribution 